\title{
The Effect of tPA on Inpatient Rehabilitation after Stroke: A Cost Comparison
}

\author{
Marina Richardson, Matthew Meyer, Robert Teasell
}

\begin{abstract}
Background: Tissue plasminogen activator has been found to significantly improve patient outcomes post stroke. Previous economic evaluations have adjusted for fewer admissions to inpatient rehabilitation but not for decreased length of stay in rehabilitation. Our objective was to estimate the potential cost savings associated with a decreased length of stay in inpatient rehabilitation for patients who receive tissue plasminogen activator compared to those who do not, in a Canadian context. Methods: Decreased length of stay in inpatient rehabilitation for patients who received tissue plasminogen activator compared to controls was reported previously in a population of 1962 patients admitted to hospital with an ischemic stroke in Ontario between July 1, 2003 and March 31,2008. Average per diem cost savings associated with the use of tissue plasminogen activator were calculated using a literature based cost estimate. Sensitivity analysis varying the length of stay in inpatient rehabilitation was performed. Results: The estimated mean per diem cost of inpatient rehabilitation derived from the literature was $\$ 626$. Based on previously reported estimates for reduced length of stay, receipt of tissue plasminogen activator was estimated to result in savings of $\$ 939$ per patient during inpatient rehabilitation. Sensitivity analysis suggested that these cost savings could range from $\$ 501$ to $\$ 1377$ per patient on average. Conclusions: Future economic evaluations of tissue plasminogen activator should consider adjusting for shortened length of stay in inpatient rehabilitation for patients who receive tissue plasminogen activator.
\end{abstract}

RÉSUMÉ: Effet de l'activateur du plasminogène tissulaire sur la réadaptation du patient hospitalisé après un accident vasculaire cérébral : comparaison de coûts. Contexte : L'activateur du plasminogène tissulaire (rt-PA) exerce un effet bénéfique significatif sur l'état des patients après un accident vasculaire cérébral (AVC). Les données des évaluations économiques antérieures ont été ajustées pour un nombre d'admissions inférieur en réadaptation hospitalière, mais non pour un séjour moins long en réadaptation. Notre objectif était d'estimer les économies potentielles associées à un séjour plus court en réadaptation hospitalière chez les patients qui reçoivent l'activateur du plasminogène tissulaire comparés à ceux qui n'en reçoivent pas dans un contexte canadien. Méthodes : Une diminution du temps de séjour en réadaptation des patients qui avaient reçu du rt-PA par rapport à des sujets témoins a été rapportée antérieurement chez 1962 patients atteints d'un AVC ischémique hospitalisés en Ontario entre le 1e juillet 2003 et le 31 mars 2008. L'économie moyenne per diem associée à l'utilisation du rt-PA a été calculée au moyen d'un estimé des coûts basé sur la littérature. Nous avons effectué une analyse de sensibilité en variant la durée de la réadaptation hospitalière. Résultats : Le coût per diem moyen estimé pour la réadaptation hospitalière selon les données tirées de la littérature était de $626 \$$. En nous basant sur des estimés de séjours plus courts rapportés antérieurement, l'économie par patient qui reçoit du rt-PA a été estimée à 939 \$ pendant la réadaptation hospitalière. L'analyse de sensibilité suggérait que ces économies pourraient être en moyenne de 501\$ à 1377 \$ par patient. Conclusions : À l'avenir, les évaluations économiques portant sur l'administration de rt-PA devraient considérer l'ajustement des données selon la durée du séjour en réadaptation hospitalière des patients qui reçoivent du rt-PA.

Can J Neurol Sci. 2014; 41: 482-485

Stroke is a significant cause of mortality and morbidity worldwide accounting for approximately 5.5 million deaths and 44 million years lost to disability annually. ${ }^{1}$ Research indicates that ischemic stroke accounts for $87 \%$ of stroke cases with up to $20-40 \%$ of these cases eligible for treatment with tissue plasminogen activator (tPA). ${ }^{2} \mathrm{~A}$ recent Canadian audit found that approximately $8 \%$ of patients presenting to hospital with an ischemic stroke received tPA. ${ }^{3}$

Among eligible ischemic stroke patients, tPA has been demonstrated to significantly increase the chance of survival and improve disability status post-stroke. ${ }^{4}$ The cost-effectiveness of tPA has also been demonstrated with studies from multiple countries indicating that tPA offers significant cost savings relative to routine care. ${ }^{5}$ These studies have demonstrated that the cost-effectiveness of tPA is largely recognized through shorter lengths of stay in the acute care setting and fewer patients requiring rehabilitation services. ${ }^{6,7}$

From the Lawson Health Research Institute (MR, MM, RT); Department of Epidemiology and Biostatistics (MM), Department of Physical Medicine and Rehabilitation (RT), Western University; St. Joseph's Health Care London (RT), Parkwood Hospital, London, Ontario, Canada.

Received January 15, 2014. Final Revisions Submitted February 24, 2014 Correspondence to: Marina Richardson, Parkwood Hospital - B3019, 801

Commissioners Road East, London, Ontario, N6C 5J1, Canada. Email: Marina.Richardson@sjhc.london.on.ca. 
Acute inpatient care costs, medication, radiation, and laboratory costs are known to account for the majority of short term stroke costs, ${ }^{8}$ however, inpatient rehabilitation has also been found to account for $8 \%$ of costs within the first 30 days, ${ }^{8}$ and $27 \%$ of first-year costs ${ }^{9}$. Current studies assessing the costeffectiveness of tPA vary in their methods for managing the costs of inpatient rehabilitation post stroke. Rehabilitation costs have been included under direct costs, indirect costs, rehabilitation costs, inpatient hospital costs or not specified at all, and are typically presented as an average cost per patient based on functional status (e.g. dependent or independent). 6,7,10-21 Regardless of how inpatient rehabilitation costs are captured, these studies only account for the differences in the proportion of patients utilizing inpatient rehabilitation and not the variation in rehabilitation length of stay (LOS). Consequently, no study to date has accurately assessed the effect of tPA on the cost of inpatient rehabilitation after stroke.

In a previously published study, our group reported that patients who received tPA demonstrated similar functional gains as clinically similar controls despite shorter average LOS in inpatient rehabilitation. ${ }^{22}$ This finding suggested that tPA may contribute to cost savings during inpatient rehabilitation above those reported in the literature.

\section{OBJective}

The objective of this study was to estimate the value of these cost savings using published per diem estimates of post-stroke inpatient rehabilitation cost.

\section{METHODS}

\section{Patients and Costs}

All analyses performed in this study are based, in part, on data published in a previous study. Detailed information on the data source, patient sample and statistical analyses are described there.22 Briefly, the sample consisted of 1962 patients from Ontario who presented to acute care with an ischemic stroke between July 1, 2003 and March 31, 2008, were admitted to inpatient rehabilitation, and were eligible for $\mathrm{tPA}^{22} \mathrm{~A}$ multivariable generalized linear model was used to estimate the average reduction in inpatient rehabilitation LOS (and confidence intervals) associated with acute tPA administration, adjusting for age, initial Canadian Neurological Scale (CNS) score, previous stroke, diabetes, and admission Functional Independence Measure (FIM $®$ ) score. ${ }^{22}$ This adjusted measure of effect was used in the current calculations to estimate potential cost savings.

Per diem cost of inpatient rehabilitation in Canada was derived from the peer-reviewed literature and inflation adjusted to 2012 equivalents using Statistics Canada's consumer price index's health and personal care inflation rate.

\section{Cost Savings and Sensitivity Analysis}

To estimate the per-patient cost savings in inpatient rehabilitation among those who received tPA compared to clinically similar controls, the average reduction in inpatient rehabilitation LOS for patients who received tPA was multiplied by the average per diem cost of inpatient rehabilitation. Sensitivity analyses were performed using the $95 \%$ confidence interval (CI) for the difference in mean LOS.

\section{RESULTS}

\section{Patients and Costs}

Detailed patient demographics and multivariable analysis results are reported in the previous study.22 A summary of relevant baseline demographic characteristics of the study sample are outlined in the Table (modified from Meyer et al 2012) $)^{22}$. The unadjusted inpatient rehabilitation LOS was 41 days for patients who received tPA and 39 days for patients who did not receive tPA. After controlling for age, baseline CNS, FIM $^{\circledR}$ on admission, diabetes, and history of stroke, patients who received tPA experienced an inpatient rehabilitation LOS that was $3.8 \%$ shorter on average $(95 \% \mathrm{CI}, 2.1 \%$ to $5.5 \%)$ than patients who did not receive $\mathrm{PAA} .^{22}$

Only one Canadian per diem cost estimate for inpatient rehabilitation was located in the peer-reviewed literature. ${ }^{23}$ No information was available regarding the costs that were included

Table: Baseline characteristics of the study sample s2 $^{22}$

\begin{tabular}{lcc}
\hline & $\begin{array}{c}\text { tPA } \\
(\mathrm{N}=448)\end{array}$ & $\begin{array}{c}\text { No tPA } \\
(\mathrm{N}=1514)\end{array}$ \\
\hline Age (Mean $\pm \mathrm{SD})$ & $68.1 \pm 14.2$ & $69.94 \pm 13.5$ \\
Male Sex (n (\%)) & $240(53.6 \%)$ & $843(55.7 \%)$ \\
Admission CNS Score (Mean \pm SD) & $5.8 \pm 2.4$ & $8.2 \pm 2.4$ \\
Previous Stroke (n (\%)) & $56(12.5 \%)$ & $292(19.3 \%)$ \\
History of Diabetes (n (\%)) & $77(17.2 \%)$ & $433(28.6 \%)$ \\
Admission FIM (Mean \pm SD) & $76.0 \pm 24.8$ & $80.0 \pm 23.6$ \\
Inpatient Rehabilitation LOS (Mean $\pm \mathrm{SD})$ & $40.9 \pm 27.6$ & $39.3 \pm 26.6$ \\
\hline
\end{tabular}

SD, standard deviation; tPA, tissue plasminogen activator; CNS, Canadian Neurological Scale; FIM ${ }^{\circledR}$, Functional Independence Measure; LOS, length of stay 
in this estimate. The 2012 inflation-adjusted Canadian dollar cost estimate was $\$ 626.13$.

\section{Cost Savings and Sensitivity Analysis}

Using a mean LOS in inpatient rehabilitation for patients who did not receive tPA of 39.3 days, and an estimated, adjusted, $3.8 \%$ decrease in LOS for patients who did receive tPA, patients who received tPA were expected to spend an average of 1.5 fewer days (95\% CI 0.8 days to 2.2 days) in inpatient rehabilitation. This equates to a cost savings of $\$ 939$ per patient who received tPA compared to a clinically similar control. Sensitivity analysis varying the estimated decrease in LOS resulted in anticipated cost savings between $\$ 501$ and $\$ 1377$ per patient.

\section{Discussion}

Using the average per diem cost derived from the literature and our previously calculated estimate for reduced rehabilitation LOS, we estimated that patients who received tPA and entered inpatient rehabilitation cost approximately $\$ 939$ less than clinically similar controls who did not receive tPA. While our results confirm that tPA is a cost-effective treatment for stroke, the additional cost savings are important to note. Thrombolytic therapy is often criticized for its high costs in the short term. ${ }^{6,21}$ Previous cost-effectiveness studies are in favour of tPA, but only after considering long-term cost savings. Because inpatient rehabilitation is typically completed within the first six months post stroke, $, 2,24$ our findings suggest that some cost savings associated with tPA may be realized earlier than previously thought.

Our objective was not to replicate the cost-effectiveness studies performed previously, but to refine a component of this information for future evaluations of tPA. Additional studies are necessary to validate the estimates generated here in other populations and regions. However, our results suggest that future cost-effectiveness studies of tPA should consider including the caveat of shortened inpatient rehabilitation stays in their models. These studies should also consider evaluating the impact of tPA on patient progress through other sectors (e.g. outpatient rehabilitation) to more accurately estimate long-term cost savings. More accurate evaluation of the long-term effects of tPA on patient outcomes and costs will help to provide a more complete picture of the impact of tPA.

\section{Limitations}

The only adjusted estimate of reduced LOS in inpatient rehabilitation after receiving tPA was our previously published estimate using Ontario data. Likewise, our cost estimate was derived from only one study. The per diem cost used here may not reflect the experience of other centres. Stroke care in Ontario is funded through a single payer model (Ontario Health Insurance Plan) and all providers are subject to the same accreditation program. Despite this uniformity, we were unable to control for differences between centres such as the availability of outpatient rehabilitation services and the rates of tPA use. Furthermore, some patient-specific variables, such as depression scores, presence of communication deficits, presence of a caregiver, and location of stroke, were not available for between- group comparisons. Our study also focused solely on patients admitted to inpatient rehabilitation and, therefore, did not seek to evaluate patients for whom the effect of tPA (positive or negative) precluded the need for inpatient rehabilitation.

\section{Conclusions}

The cost-effectiveness of tPA has been well documented previously. Ontario data suggest that during inpatient rehabilitation, patients who receive acute tPA experience additional cost savings that have not been reflected in previous cost-effectiveness analyses. Future studies may want to validate this finding in regions outside of Ontario, to update previous cost-effectiveness assessments, and to explore other modelling assumptions that may be overlooking cost savings associated with tPA.

\section{REFERENCES}

1. Mukherjee D, Patil CG. Epidemiology and the global burden of stroke. World Neurosurg. 2011;76(6 Suppl):S85-90.

2. Hirsch JA, Yoo AJ, Nogueira RG, et al. Case volumes of intraarterial and intravenous treatment of ischemic stroke in the USA. J Neurointerv Surg. 2009;1(1):27-31 .

3. Canadian Stroke Network. Canadian Stroke Network [homepage on the Internet]. Ottawa: Canadian Stroke Network; 2011. The quality of stroke care in Canada; 2011 [cited 2013 Jan 7]. Available from: http://www.canadianstrokenetwork.ca/wpcontent/uploads/2011/06/QoSC-EN1.pdf.

4. Wardlaw JM, Murray V, Berge E, et al. Recombinant tissue plasminogen activator for acute ischaemic stroke: An updated systematic review and meta-analysis. Lancet. 2012;379(9834): 2364-72.

5. Jung KT, Shin DW, Lee KJ, Oh M. Cost-effectiveness of recombinant tissue plasminogen activator in the management of acute ischemic stroke: a systematic review. J Clin Neurol. 2010;6 (3):117-26.

6. Fagan SC, Morgenstern LB, Petitta A, et al. Cost-effectiveness of tissue plasminogen activator for acute ischemic stroke. Ninds rtpa stroke study group. Neurology. 1998;50(4):883-90.

7. Sinclair SE, Frighetto L, Loewen PS, et al. Cost-utility analysis of tissue plasminogen activator therapy for acute ischaemic stroke: A Canadian healthcare perspective. Pharmacoeconomics. 2001; 19(9):927-36.

8. Demaerschalk BM, Hwang HM, Leung G. Cost analysis review of stroke centers, telestroke, and rt-pa. Am J Manag Care. 2010;16 (7):537-44.

9. Dewey HM, Thrift AG, Mihalopoulos C, et al. Cost of stroke in Australia from a societal perspective: Results from the north east melbourne stroke incidence study (nemesis). Stroke. 2001;32 (10):2409-16.

10. Araujo DV, Teich V, Passos RB, Martins SC. Analysis of the costeffectiveness of thrombolysis with alteplase in stroke. Arq Bras Cardiol. 2010;95(1): 12-20.

11. Boudreau DM, Guzauskas G, Villa KF, Fagan SC, Veenstra DL. A model of cost-effectiveness of tissue plasminogen activator in patient subgroups 3 to 4.5 hours after onset of acute ischemic stroke. Ann Emerg Med. 2013;61(1):46-55.

12. Chambers MG, Koch P, Hutton J. Development of a decisionanalytic model of stroke care in the United States and Europe. Value Health. 2002;5(2):82-97.

13. Dirks M, Baeten SA, Dippel DW, et al. Real-life costs and effects of an implementation program to increase thrombolysis in stroke. Neurology. 2012;79(6):508-14.

14. Earnshaw SR, Jackson D, Farkouh R, Schwamm L. Costeffectiveness of patient selection using penumbral-based MRI for intravenous thrombolysis. Stroke. 2009;40(5):1710-20.

15. Ehlers L, Muskens WM, Jensen LG, Kjolby M, Andersen G. National use of thrombolysis with alteplase for acute ischaemic 
stroke via telemedicine in Denmark: A model of budgetary impact and cost effectiveness. CNS Drugs. 2008;22(1):73-81.

16. Ehlers L, Andersen G, Clausen LB, Bech M, Kjolby M. Costeffectiveness of intravenous thrombolysis with alteplase within a 3-hour window after acute ischemic stroke. Stroke. 2007;38(1): 85-9.

17. Mar J, Begiristain JM, Arrazola A. Cost-effectiveness analysis of thrombolytic treatment for stroke. Cerebrovasc Dis. 2005;20(3): 193-200.

18. Moodie ML, Carter R, Mihalopoulos C, et al. Trial application of a model of resource utilization, costs, and outcomes for stroke (morucos) to assist priority setting in stroke. Stroke. 2004;35(5):1041-6.

19. Sandercock P, Berge E, Dennis M, et al. Cost-effectiveness of thrombolysis with recombinant tissue plasminogen activator for acute ischemic stroke assessed by a model based on UK NHS costs. Stroke. 2004;35(6):1490-7.
20. Stahl JE, Furie KL, Gleason S, Gazelle GS. Stroke: Effect of implementing an evaluation and treatment protocol compliant with ninds recommendations. Radiology. 2003;228(3):659-68.

21. Tung CE, Win SS, Lansberg MG. Cost-effectiveness of tissue-type plasminogen activator in the 3- to 4.5-hour time window for acute ischemic stroke. Stroke. 2011;42(8):2257-62.

22. Meyer M, Murie-Fernandez M, Hall R, et al. Assessing the impact of thrombolysis on progress through inpatient rehabilitation after stroke: A multivariable approach. Int J Stroke. 2012;7(6):460-4.

23. Mittmann N, Seung SJ, Hill MD, et al. Impact of disability status on ischemic stroke costs in Canada in the first year. Can J Neurol Sci. 2012;39(6):793-800.

24. Chambers M, Hutton J, Gladman J. Cost-effectiveness analysis of antiplatelet therapy in the prevention of recurrent stroke in the UK. Aspirin, dipyridamole and aspirin - dipyridamole. Pharmacoeconomics. 1999;16(5 Pt 2):577-93. 